shows how Pasteur's method of approach never varied and still stands as a model for men of science everywhere. It is indeed a tribute to a man whose father served with Napoleon that his methods are now being applied to the solution of industrial problems. Nicolle's book can take its place as a worthy successor to René Vallery-Radot's admirable La Vie de Pasteur and Les Oeuvres de Pasteur, which owed so much to its editor, Pasteur Vallery-Radot.

T. H. Hawkins

\section{TERPENE PROPERTIES AND STRUCTURES}

\section{Die Terpene}

Sammlung der Spektren und Physikalischen Konstanten. Von J. Pliva, M. Horák, V. Herout und F. Sorm. Teil 1 : Sesquiterpene. Pp. xxii +1-228. (Deutsche Akademie der Wissenschaften zu Berlin Kommission für Spektroskopie.) (Berlin: AkademieVerlag, 1960.) n.p.

T HIS work is not a compilation of analytical data from all available sources. It is designed not only as an aid to the identification of terpenes but also as material for the study of relations between the infra-red spectra and molecular structure. Advisedly limiting the former objective for the better attainment of the latter, the authors include only physical data determined on the identical sample used for the infra-red work. Largely, therefore, this is a report on a consistent plan of laboratory work, over about twelve years, by a single team at the Czechoslovakian Academy of Sciences.

The plan provides for the fractionation of essential oils, by a standardized technique of distillation followed by alumina-column chromatography, into constituents in which further treatment produces no change of physical characters, including infra-red absorption. These isolates are investigated and classified primarily on the basis of infra-red spectra. Most, though not all, are compounds previously known; but the Prague group has been prominent in the work which in recent years has led to the revision or final elucidation of the structures of such long-known compounds as caryophyllene and humulene (to which, respectively, 9- and 11 -membered rings are now assigned), as well as the successful investigation of such new terpenes as the acoran series from calamus oil, embodying spiro-linked 5- and 6 -membered rings.

The criterion for classification of a compound is the infra-red spectrum of the saturated hydrocarbon formed by its complete hydrogenation, using Adams's catalyst at room temperature. As a means of investigating structure, it is claimed that this technique, compared with Ruzicka's dehydrogenation procedure, has more general applicability, less risk of altering the carbon skeleton, and has higher yields, permitting of work on smaller quantities. From twenty to thirty carbon skeletons are thus recognized among the sesquiterpenes, and these are named by modification of familiar, or at least identifiable, trivial names, for example, caryophyllan from caryophyllene, zieran from zierone. Sub-groups such as vetivan, isovetivan and neovetivan provide for the cis-trans isomerism which may arise naturally or in the course of the hydrogenation.
217 natural or artificial sesquiterpenes are described, each on its own card (British Standard $A 4$ size). A complete card gives molecular and graphic (though not steric) formulæ, density, refractive index and specific rotation, boiling-point (under low pressure) or melting-point, ultra-violet absorption characters if any, a brief indication of source and means of purification, literature references on isolation and constitution, and an infra-red transmittance curve from 650 to 1,500 or $2,000 \mathrm{~cm}^{-1}$, as appropriate, in a rock-salt prism instrument of resolving power $2-3$ at 650 and $7-10$ at $2,000 \mathrm{~cm}^{-1}$. Experimental data on film thickness, solvent, etc., are supplied.

Indexing, both by classes and by individuals, is adequate. The type correctly indexed as "eremophilan" appears in the structure-key as "eremophyllan".

Further publication on the monoterpenes and higher terpenes, and on the results of gas-chromatographic or other improved methods of separation, is contemplated.

E. G. KeLLeTt

\section{SERVOMECHANISMS}

\section{Control Engineering}

(The Van Nostrand Series in Electronics and Communications.) By Prof. Gordon J. Murphy. Pp. xii + 385. (Princeton, N.J.: D. Van Nostrand Company, Inc; London: D. Van Nostrand Company, Ltd., 1959.) $56 s$.

THrs book presents in some detail the mathematical theory of linear servomechanisms, and, without treating any particular topic exhaustively, describes its application to several different types of system. Techniques for non-linear systems are confined to the two final chapters. So many books have now been published in this field it is probably appropriate to describe in some detail the contents of the present text. After a very general introductory chapter, the second deals with the Laplace transform, the transfer function and related stability considerations under the heading of "Time Response". There follows an excellent chapter on design in the $s$-plane which concludes with a description of the root-locus method. The use of this method is very much a matter of practical experience, but many readers would none the less welcome rather more discussion of its application than is actually included. These two chapters are complemented by the next on frequency response, which covers well-trodden ground in a clear style with several examples to illustrate theory. The three following chapters deal with specific types of system, namely the carrier-control, dead-time and sampled-data systems. A chapter on noise concludes the treatment of linear servomechanisms. The two chapters on the analysis of non-linear systems deal with the describing function and the phase-plane technique.

The text throughout proceeds from the general to the particular, an approach which tends in places somewhat to obscure, or postpone, full appreciation of the significance of a result or technique. The work is therefore not suitable as an introduction to the subject, but forms a useful and clearly written work at a more advanced level.

Problems are included at the end of each chapter, and a table of fifty-two Laplace transforms is included as an appendix.
E. M. Deeley 